\title{
Medical care of long-stay patients in psychiatric wards
}

The College reaffirms unequivocally that the consultant psychiatrist retains the ultimate responsibility for all aspects of medical care of an in-patient under his charge.

This applies whether the patient is in an admission ward or in a long-stay psychiatric ward, and whether clinical assistants are employed or not. The only possible exception is when another consultant, by joint agreement, agrees to take over responsibility for part or whole of the patient's medical care.

The College believes that supervised experience is in the care of long-stay patients constitutes an important part of the education of a psychiatrist and should be a part of all training programmes and preferably at all levels (SHO, registrar and senior registrar).

Where the day to day clinical care of long-stay patients is carried out by doctors in the training and other grades, the consultant should ensure that a systematic supervision of this process takes place, and should play an active role in this himself.

When a doctor is on-call for psychiatric in-patients, it should be assumed that his duties encompass the total medical needs of the patient unless there is an explicit alternative arrangement locally. To quote from an earlier College statement 1 "A Consultant has the ultimate responsibility and the overall authority to diagnose illness and prescribe treatment. This authority may be delegated, but the responsibility cannot be abrogated. ...

\section{Rereance}

${ }^{2} R A W N s L E Y, K$. (1984) The future of the consultant in peychiatry. A report to the College. Bulletin of the Royal College of Psychiatrists, 8, 122-123.

Approved by Council June 1986

\section{Clinical Psychologists and Psychiatric Services}

In future, Psychology Services are increasingly likely to be provided on a District Basis with referrals coming from all parts of the Hospital and Primary Care services. Traditionally, psychologists have been supported by funds provided from the psychiatric services. This may change in the future, and there is considerable anxiety among both psychiatrists and some psychologists, that psychologists' time will be increasingly diverted away from other patients suffering from severe psychiatric illness or from other serious psychological handicaps. The College therefore urges that all members should make representations to General and District Managers that the sessional allocations of all psychologists, both in existing posts and in those being planned for the future, should include some defined commitment of sessions to the psychiatric services.

J. L. T. BIRLEY Dean Approved by Council June 1986

\section{Public Education in Psychiatry}

The College is embarking on a public relations exercise in an attempt to fulfil one of the obligations laid out in its Charter, namely to further public education in the science and practice of psychiatry. If you have written any papers, leaflets, books etc. about specific areas of psychiatry and which would be easily understood by the layperson, I would be most grateful if you could send a copy to the College Secretary as soon as possible.

C. M. B. PARE 